\title{
Ultrasound for Critical Care Physicians: Atypical Headache
}

A 76 year old woman presented with complaints of a new onset of headache especially on the right. Brain CT scan and MRI were unremarkable. Her erythrocyte sedimentation rate was markedly elevated. An ultrasound of the chest was performed (Figures 1 and 2).

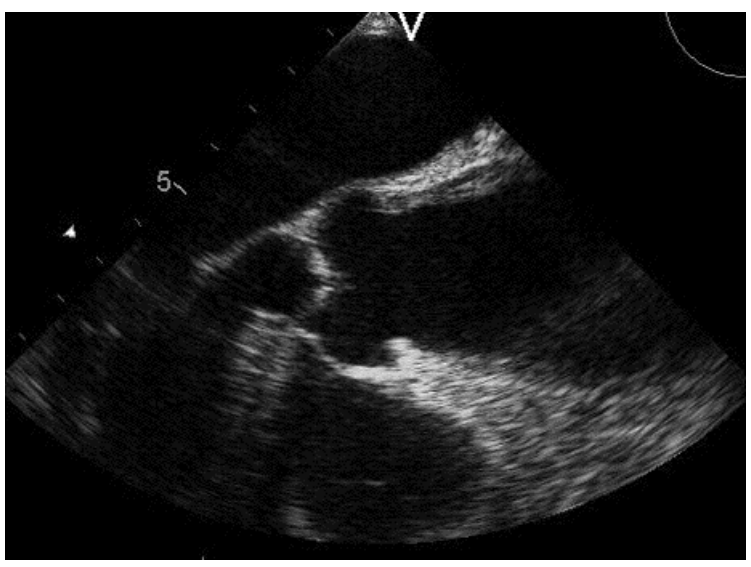

Figure 1. Long axis view through the aortic valve area.

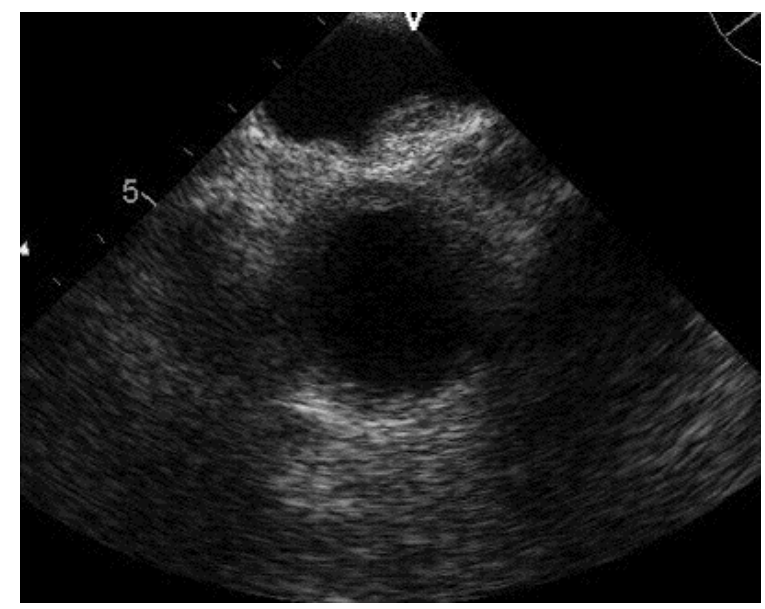

Figure 2. Transverse view through the aorta.

What does the ultrasound show?

1. Aortic aneurysm

2. Aortic insufficiency

3. Aortic stenosis

4. Aortic wall thickening

5. 1 and 2

6. 1 and 4

7. 2 and 4 


\section{Correct!}

\section{1 and 4}

The ultrasound shows a thoracic aortic aneurysm and aortic wall thickening. The markedly elevated sedimentation rate in the setting of an aneurysm or vasculitis suggests giant cell arteritis, and corticosteroids should be started as soon as giant cell arteritis is suspected to prevent blindness (1). However, vascular wall thickening at imaging is not specific for arteritis and can be caused by acute aortic syndromes, such as intramural hematoma or thrombosis of the false lumen of an aortic dissection (2). Such abnormalities are urgent findings and may be difficult to distinguish from vasculitis on ultrasound, and should be evaluated with thoracic CT or MR. The wall thickening proved to be an intramural hematoma on thoracic CT scan. Unfortunately, the patient had further dissection of her aneurysm and was referred to hospice.

Michael B. Gotway, MD

Department of Radiology

Mayo Clinic Arizona

\section{References}

1. Waldman CW, Waldman SD, Waldman RA. Giant cell arteritis. Med Clin North Am. 2013;97(2):329-35. [CrossRef] [PubMed]

2. Pandit A, Panse PM, Gruden JF, Gotway MB. Pulmonary artery sheath haematoma with pulmonary arterial compression: a rare complication of type A aortic dissection mistaken for aortitis. Eur Heart J. 2013 Jun 20 [Epub ahead of print] [CrossRef] [PubMed] 